\title{
Online Mentoring as an Extracurricular Measure to Encourage Talented Girls in STEM (Science, Technology, Engineering, and Mathematics): An Empirical Study of One-on-One Versus Group Mentoring
}

\author{
Heidrun Stoeger', Manuel Hopp ${ }^{2}$, and Albert Ziegler ${ }^{2}$
}

\begin{abstract}
Online mentoring provides an effective means of extracurricular gifted education for talented girls in science, technology, engineering, and mathematics (STEM). Comparative studies on the effectiveness of one-on-one versus group mentoring are lacking, however. The authors investigated this question in the context of a Germany-wide online mentoring program that employed both approaches. Study participants were girls enrolled in high-achiever-track secondary education in Germany $(N=347)$ who were mentored online by female academics in STEM for 6 months, in either one-on-one $(N=156)$ or group mentoring $(N=191)$. It was assumed that the specific many-to-many group-mentoring condition examined in our study would be more effective than the one-on-one mentoring condition with respect to (a) the proportion of STEM communication and (b) the extent of STEM-related networking, both of which are important predictors of successful mentoring. Furthermore, the authors (c) expected more growth in elective intentions for the group-mentoring participants and (d) assumed that participants' centrality in their respective STEM networks would predict this increase. The study presents empirical support for all four assumptions and thus suggests that the special form of group mentoring examined here may be a more successful measure of extracurricular gifted education for girls in STEM than one-on-one mentoring.
\end{abstract}

\section{Keywords}

mentoring, gifted girls, STEM, network analysis, gifted education, online gifted education

Record numbers of women are entering science, technology, engineering, and mathematics (STEM) subjects and careers. Nevertheless, they remain underrepresented in STEM in most countries. The imbalance is greatest in engineering and computer science (Statistisches Bundesamt, 2015). When females demonstrate similar or greater talent levels or even better grades than males, they are nevertheless more likely to not choose a STEM major or career (Wang, Eccless, \& Kenny, 2013). The underrepresentation of females is problematic for individuals and societies. STEM fields facilitate lucrative, high-status careers with considerable innovation potential (Kalwarski, Mosher, Paskin, \& Rosato, 2007). At the societal level, an increase in the rates of females in STEM can help reduce the skilled-labor shortage in STEM and increase the overall number of talented persons working in STEM.

As girls' interest in STEM decreases over the course of schooling (Frenzel, Goetz, Pekrun, \& Watt, 2010), programs designed to get more females interested in STEM need to be offered to girls early. In the case of gifted education in particular, it is important that in-school and extracurricular gifted education programs be combined (OlszewskiKubilius, 2009). One possibility for effective extracurricular education for girls in STEM is mentoring. It sustains talented girls' interest in STEM (Pfund, Pribbenow, Branchaw, Lauffer, \& Handelsman, 2006), and it is a viable option within gifted education (Subotnik, Edmiston, Cook, \& Ross, 2010). As will be explained later, online mentoring is particularly useful for getting talented female secondary school students excited about STEM. Despite this potential, however, little is known about whether one-on-one mentoring or group mentoring is more effective. It is conceivable that oneon-one mentoring is particularly effective on account of the very individual sort of guidance it provides. At the same time, however, it is possible that group mentoring using a

\footnotetext{
'University of Regensburg, Regensburg, Bavaria, Germany

${ }^{2}$ University of Erlangen-Nuremberg, Nuremberg, Germany

Corresponding Author:

Heidrun Stoeger, University of Regensburg, Universitätsstr. 3I,

Regensburg, Bavaria 93053, Germany.

Email: heidrun.stoeger@ur.de
} 
many-to-many approach is actually more effective at increasing STEM participation rates as a many-to-many approach offers mentees insights into various fields of endeavor within STEM. In this sense, it should do a better job of making mentees cognizant of the variety of fields and branches of knowledge within STEM.

One aim of our present study was to compare the effectiveness of one-on-one versus group online mentoring in STEM for high-achieving girls in secondary school. Furthermore, we examined the conditions under which online group mentoring is particularly effective.

\section{Online Mentoring for Talented Girls in STEM}

Most definitions characterize online mentoring as a special form of mentoring in which at least some of the communication takes place electronically. O'Neill, Wagner, and Gomez (1996) describe online mentoring as the "use of e-mail or computer conferencing systems to support a mentoring relationship when a face-to-face relationship would be impractical" (p. 39). Bierema and Merriam (2002) describe a "computer mediated, mutually beneficial relationship between a mentor and a protégé which provides learning, advising, encouraging, promoting, and modelling, that is often boundaryless, egalitarian, and qualitatively different than face-to-face mentoring" (p. 212). While some researchers view online mentoring as a makeshift solution when offline mentoring is not possible, others stress the unique advantages of online mentoring.

For gifted education provision for girls in STEM, the advantages of online mentoring clearly outweigh potential drawbacks (for an overview, see Miller \& Griffiths, 2005). Appropriate program planning can easily overcome known drawbacks. We now describe four aspects that are important for successful gifted education provision for girls in STEM and can be implemented particularly effectively via online mentoring.

First, successful female role models are crucial for supporting girls in STEM (e.g., Stout, Dasgupta, Hunsinger, \& McManus, 2010). As the participation rates of women in STEM are still low, finding a sufficient number of professional women in STEM is difficult, however. The task becomes even more difficult when one also considers other empirically substantiated criteria of adequate role models and effective mentoring relationships such as the use of nonstereotypical role models (Cheryan, Drury, \& Vichayapai, 2013) and mentoring dyads consisting of optimally matched partners (DuBois, Holloway, Valentine, \& Cooper, 2002). By enabling mentoring relationships across large geographical distances and thus dramatically increasing the potential pool of qualified mentors, online mentoring helps solve these problems (Packard, 2003).

Second, girls' STEM interests already start declining during secondary school (Frenzel et al., 2010). Intervention programs therefore need to reach students before their interests in STEM decline. However, participation in off-line mentoring programs is often logistically difficult for younger mentees. Meetings with a mentor may require an accompanying adult, who may also need to furnish transportation. Furthermore, mentors' and mentees' schedules tend to be incompatible, with girls having more time during the day and the mentors' free time often being limited to evenings and weekends. Online mentoring can help overcome logistical barriers that apply to young mentees in particular.

Third, studies indicate that the regularity and the frequency of mentor-mentee interaction determine the success of mentoring (DuBois et al., 2002). By enabling asynchronous communication (e.g., via e-mail or in forums) and geographical and scheduling flexibility, online mentoring programs help achieve sufficient levels of interaction frequency.

Fourth, in addition to role models of a higher status, sameage and same-status role models are also important (Dasgupta, 2011). Online mentoring programs open up the possibility of creating members-only online community platforms that offer simultaneous access to large numbers of mentors and mentees, ensuring that mentees interact with a variety of different role models at any given time.

Despite extensive research on off-line youth mentoring (e.g., DuBois \& Karcher, 2005; DuBois, Portillo, Rhodes, Silverhorn, \& Valentine, 2011), studies of online youth mentoring are few in number and just starting to appear (e.g., O’Neill, Asgari, \& Dong, 2011; Penny \& Bolt, 2009). Existing evaluation studies in both areas evince methodological shortcomings (e.g., reliance on satisfaction surveys, lack of longitudinal designs, missing or questionable controltreatment group designs; for an overview, see Ensher, Heun, \& Blanchard, 2003).

The few methodologically acceptable studies of online mentoring in STEM with talented girls that have been published indicate that such programs are effective. The mentees in one online mentoring program (CyberMentor) showed both short-term and long-term improvements in their knowledge about university studies and jobs in STEM as well as in their certainty about academic and career goals in STEM. The participants' improvements were in comparison to control groups of boys and girls who were attending the same type of secondary schooling and had not signed up for the program. The improvements also held when the participants were compared to a wait list control group of girls who were attending the same type of secondary schooling and had also registered for the program but had been asked to wait one year before participating (Stoeger, Duan, Schirner, Greindl, \& Ziegler, 2013; Stoeger, Schirner, Laemmle, Obergriesser, Heilemann, \& Ziegler, 2016). The comparison with the wait list control group is particularly important. It provides evidence that the participants' positive changes are a result of program participation and do not merely reflect characteristics of the girls who registered for such a program.

The CyberMentor program initially focused on one-onone mentoring (Stoeger et al., 2014). Students in the program were matched with a personal female mentor, who was either 
a graduate student enrolled in a STEM program or a professional working in STEM. Over the course of one year, mentees and mentors communicated with one another at least once weekly via e-mail. Participants could also communicate via chat, forum, and e-mail with several hundred other program participants (other female mentees and mentors) on the members-only online platform. Crucially, the propitiousness of mentees' developmental trajectories correlated positively with the extent to which the participants communicated about STEM topics during program participation (Stoeger et al., 2016). This finding raises the question of whether online mentoring in a group structure (group mentoring) rather than one-on-one mentoring is perhaps a more effective option for providing extracurricular gifted education for girls in STEM, as group mentoring may allow for more extensive networking among the participants and thereby facilitate a greater amount of STEM communication.

\section{Group Mentoring in STEM for Talented Girls}

Various definitions of group mentoring exist (for an overview, see Bozeman \& Feeney, 2007). It is commonly understood as a format of mentoring wherein multiple mentees interact and form relationships with one or more mentors (Kuperminc \& Thomason, 2013). Characteristics distinguishing group mentoring from cooperative groups include differences in relevant knowledge, wisdom, or experience as well as transmission of knowledge, social capital, or psychological support, which primarily occurs through informal communication. Finally, the interaction needs to have a direct influence on the individual, for instance, on careers, achievements, or personal development (Huizing, 2010). These requirements distinguish group mentoring from cooperative groups but not from one-on-one mentoring. Unlike one-on-one mentoring, group mentoring involves a polyad mentoring relationship of more than two people in which the interactions are collaborative and include all individuals in the mentoring group. It follows, furthermore, that constellations in which one person has several independent mentors - who each only interact with the same mentee and not with one other - do not qualify as group mentoring.

Four primary types of group mentoring can be distinguished: one-to-many, many-to-one, peer group, and manyto-many mentoring. In one-to-many mentoring, one mentor supports many mentees. In many-to-one mentoring, a constellation of mentors supports a single mentee. In peer group mentoring and in many-to-many mentoring, two or more participants are clearly distinguished by their mentoring role. While in peer group mentoring the role of mentor shifts within the group, many-to-many mentoring identifies the role of mentor for the life of the group according to characteristics such as greater amounts of knowledge, wisdom, or experience (for an overview, see Huizing, 2010).

Group mentoring using the many-to-many approach should be especially promising (Huizing, 2010) for extracurricular gifted education for girls in STEM as it ensures a plurality of appropriate role models for mentees. Having more than one mentor helps each individual mentee avoid viewing her respective mentor as a sort of exception to the rule (Richards \& Hewstone, 2001). Moreover, the interaction with mentors representing various STEM fields provides the mentees with insights into different possibilities for studying and working in STEM. It also facilitates the establishment of richer networks consisting of individuals from numerous STEM fields. Many-to-many group mentoring also allows mentoring programs to systematically include same-age female role models. This helps ensure that mentees do not perceive STEM as unfeminine (Kessels, Heyder, Latsch, \& Hannover, 2014). Girls' decisions to persist in STEM during postsecondary education depend more on peer support than boys' do (Schoon \& Eccles, 2014). It is also possible that the multiperson interaction inherent in all forms of group mentoring leads to greater levels of STEM communication and networking, both of which are important aspects of successful mentoring (Blickle, Witzki, \& Schneider, 2009; Stoeger et al., 2016).

Yet many-to-many group mentoring may also have its drawbacks for mentoring effectiveness. In particular, the potential for a diffusion of responsibility arises when too many individuals are involved. Furthermore, cognitive constraints (Dunbar, 1993) limit the extent of networking between people. Whether and under which conditions online mentoring for girls in STEM is more successful as a group rather than oneon-one mentoring and which characteristics of networking are particularly effective have yet to be studied. Finding initial answers to these questions was the focus of our study.

\section{Current Study}

There are indications that online mentoring is a viable option for getting more talented girls involved in STEM. Numerous examples of encouragement programs exist. Evaluation studies fulfilling methodological standards are very few in number, however. These studies suggest that online mentoring can effect increases in STEM participation rates (Stoeger et al., 2013; Stoeger et al., 2016). Yet the online mentoring programs that have been rigorously evaluated are all based on one-on-one mentoring approaches. Despite their lack of applicability to the specific question, the studies described above suggest that online mentoring in the form of group mentoring may be even more effective than one-on-one mentoring. However, a complete lack of studies comparing both approaches to mentoring in the context of extracurricular gifted education in STEM for girls means that answers require further research.

Hence, our central research question-whether online group mentoring is more effective for talented secondary school girls than one-on-one mentoring-leads to four aims for this study. First, we assessed whether the proportion of STEM communication was greater during group mentoring than during one-on-one mentoring. This question is important, as the extent of on-topic communication influences 
mentoring success (DuBois et al., 2002; Stoeger et al., 2016). Second, we considered whether group mentoring facilitates networking (with three indicators of successful networking being (a) more STEM-related contacts, (b) larger STEM networks, and (c) the individuals' centrality in their STEM networks). This is also important for education in STEM for girls, as access to a variety of STEM-related information from different persons should help the mentees develop a more detailed, in-depth picture of STEM majors and careers and thereby facilitate greater mentoring success (Blickle et al., 2009; Leydesdorff, 2007). Third, we assessed whether group mentoring effects a greater increase in mentees' academic and professional elective intentions in STEM in comparison to one-on-one mentoring. Fourth, we considered whether particular network characteristics predicted an increase in participants' elective intentions. Findings on collaboration networks suggest that girls with a more central position in their respective STEM networks will show particularly large improvements in their elective intentions in STEM (Freeman, Roeder, \& Mulholland, 1979). In a prestudy with a smaller sample of 82 mentees participating in the group-mentoring condition of the CyberMentor program, we found preliminary evidence for a positive influence of the mentees' centrality in their respective STEM networks on mentoring outcomes. The more central mentees were in their respective networks, the stronger their elective intentions in STEM were after 6 months of mentoring (even after controlling for mentees' preparticipation elective intentions in STEM). However, due to the small sample size, we observed only a marginally significant standardized regression weight of the betweenness centrality, $\beta=.13, t(79)=$ $1.66, p=.051$. Thus, the fourth aim of our study was to replicate this finding with a sufficient sample size.

\section{Method}

\section{The Online Mentoring Program CyberMentor as a Study Setting}

We investigated our research questions with data from CyberMentor, an online mentoring program in STEM for gifted girls designed to increase the participation rates of talented girls in STEM. After 6 years of operation, the program shifted from one-on-one to group mentoring (Stoeger et al., 2014). Comparing one-on-one and group mentoring within the same program ensured that all other aspects of the mentoring procedure and experience were comparable. An additional advantage of using CyberMentor is that its group mentoring reflected a many-to-many approach in which mentoring polyads always consisted of two mentees and two mentors. This mentoring structure allows for a greater amount of networking than one-on-one mentoring; by limiting polyad size to four participants, the structure also prevents responsibility diffusion. Finally, the program is advantageous for the investigation of our research question in that both variants of the mentoring program also allowed for additional networking of mentees and mentors beyond the mentoring dyads and polyads. This feature provided additional information with which we more thoroughly examined the influence of networking conditions on mentoring success.

From 2006 to 2011, CyberMentor offered one-on-one mentoring (Stoeger et al., 2014). Each mentee received guidance from a personal mentor. Mentees were encouraged to ask their mentors about STEM majors and careers and discuss interesting STEM topics with them. Starting in 2012, the program changed to group mentoring (Stoeger et al., 2014). Mentoring communities then consisted of two mentees and two mentors. All other program parameters remained unchanged. Mentees were girls (aged 11-18) attending highachiever-track secondary schools in Germany. Mentors were women with a university education in STEM who were doing graduate work in STEM or working in another professional context in STEM. Participants communicated via a members-only online platform using internal e-mail, forum, and chat functions. Besides communicating with their personal mentors and, in the case of the group mentoring, within their four-person mentoring community, program participants were also able to communicate with all other program participants (several hundred participants per year). Participation was free of charge to mentees. Mentors volunteered their time. In registering for the program, all participants committed themselves to a minimum of once-weekly exchanges via e-mail with their individual mentor or mentee or, in the case of the group mentoring, within their four-person mentoring community.

\section{Sample and Procedure}

We compared mentees $\left(N=156 ; M_{\text {age }}=14.13\right.$ years, $S D_{\text {age }}=$ 2.00 years) from the 2011 one-on-one mentoring year with mentees $\left(N=191 ; M_{\text {age }}=14.32\right.$ years, $S D_{\text {age }}=1.94$ years $)$ from the 2014/2015 group-mentoring year. All students were first-time program participants. All mentees were asked to fill out an online questionnaire about their academic and professional intentions before the mentoring year (T1) and after 6 months of mentoring (T2). Between T1 and T2, program participants' platform communication was recorded via log files. We only analyzed participants' platform-internal e-mail communication, as only the e-mail communication was mandatory for all participants.

To ensure that all study participants possessed a sufficient minimum level of commitment to the program, we included only participants in our analyses who wrote at least three STEM-related e-mails during the time period of the study, resulting in $N=140$ mentees in the one-on-one mentoring condition and $N=173$ mentees in the group-mentoring condition. We assessed STEM-related e-mails with the textanalysis program Linguistic Inquiry and Word Count (Pennebaker, Booth, \& Francis, 2007) and a STEM-word 
dictionary consisting of 1,926 words (Heilemann, 2016). For the one-on-one mentoring group, 24,995 anonymized e-mails were analyzed, 7,448 $(29.80 \%)$ of which contained at least one STEM word. The group-mentoring group wrote 28,635 e-mails, 9,643 (33.68\%) of which were STEM related.

To ensure that we were actually testing one-on-one mentoring against group mentoring, we restricted our sample of mentees from the group-mentoring year (for our first three research questions) to those mentees who had communicated at least once about STEM in a network of at least three persons. Seventy-four mentees fulfilled this criterion. The remaining group-mentoring mentees did not use the group mentoring as planned. They only communicated with one mentor or they only networked with program participants outside of their four-person community. For our fourth research question (the influence of centrality in the STEM network on the increase in elective intentions), we considered all mentees in the group-mentoring year who had composed at least three STEM e-mails $(N=173)$. Here we did not consider with how many or with which program participants (within or outside of their mentoring community) the mentees had networked via STEM e-mails. To achieve a statistical power of $80.00 \%$ with the effect size of 0.047 we required a sample size of $N=135$ (one-sided hypothesis testing). Thus, our sample size of $N=173$ allowed us to detect a significant effect with a probability of $80.16 \%$ (calculated with $\mathrm{G}^{*}$ Power, Version 3.1.9.2; Faul, Erdfelder, Buchner, \& Lang, 2009).

\section{Variables}

STEM Communication. For STEM communication, we considered the number of STEM e-mails sent by each mentee, the number of STEM words in the e-mails, and the proportion of STEM words to all words in the e-mails. Following the word list procedure described earlier (Heilemann, 2016), we collected information about these variables by analyzing the e-mails sent by the mentees over the online platform during 6 months of mentoring.

Number of sent STEM e-mails. The automated comparison of the words in the e-mails written by each mentee against the STEM-word dictionary allowed us to identify those e-mails as STEM e-mails that contained one or more STEM words. Values ranged from 3 to 86 STEM e-mails per mentee.

Number of STEM words. The number of STEM words written by each mentee was calculated by adding up the number of STEM words (as identified according to our STEM-word list) identified in the e-mails of each mentee. Values ranged from 4 to 294 STEM words per mentee.

Proportion of STEM words. We calculated the proportion of STEM words for each mentee by dividing the number of STEM words she wrote by the total number of words she wrote in all of her e-mails. Values ranged from $0.11 \%$ to $4.45 \%$.

STEM-Related Networking. For STEM-related networking, we considered the number of each mentee's STEM contacts, the size of each mentee's STEM network, and her centrality in her respective network.

Number of STEM contacts. Program participants were counted as STEM contacts when they had received at least one STEM e-mail from a mentee during mentoring. To distinguish between sent and received e-mails, we used the software package Cytoscape (Version 3.4.0; see Shannon et al., 2003) to construct communication networks based on the program participants' (i.e., mentees' and mentors') e-mails.

If mentee "A" wrote mentor " $\mathrm{B}$ " five STEM e-mails, the software depicted a directed connection from " $\mathrm{A}$ " to " $\mathrm{B}$ " with a so-called weight of 5 . The number of a mentee's STEM contacts thus reflected her outdegree (i.e., the number of outgoing connections within the given communication network). Values for STEM contacts ranged between 1 and 33 in the one-on-one mentoring group and between 1 and 24 in the group-mentoring group.

Size of the STEM network. We used a Cytoscape add-on, clusterMaker2 (Version 0.9.5), to assess the size of each mentee's STEM network. Using the option "ConnectedComponents Cluster," we identified all STEM networks and counted the number of participants per network. Figure 1 depicts a STEM network for "Mentee 1" (Me1). Mentees are represented by the black squares; the mentors are represented by the empty squares. The connections between network members as illustrated by directed arrows represent STEMrelated e-mail communication consisting of at least three e-mails. Non-STEM e-mails are not included. The thicker the line, the more STEM e-mails the participants wrote. Mentee 1 (Me1), Mentor 1 (Mo1), Mentee 2 (Me2), and Mentor 2 (Mo2) form a community on CyberMentor (as indicated by the dotted rectangle). Additionally, Me1 exchanged STEM e-mails with Mentee 3 (Me3), who was located outside of Me1's community. Through their connections, they form a STEM network of size 5. Thus, if the size of a mentee's STEM network is 2, this means she only exchanged STEM e-mails with her mentor. If a mentee's STEM network size is 5 (as in Figure 1), this means there were 5 participants who exchanged STEM e-mails (mentees and mentors, including the respective mentee).

For our examination of the first three research questions, we included only those mentees in the group-mentoring condition who belonged to a STEM network with a size of at least 3. In light of this inclusion criterion, we corrected downwards the value for the size of the STEM networks in the group-mentoring condition. This ensured that our test of the two mentoring conditions was fair. We subtracted 1 from the value of the group size (adjusted 


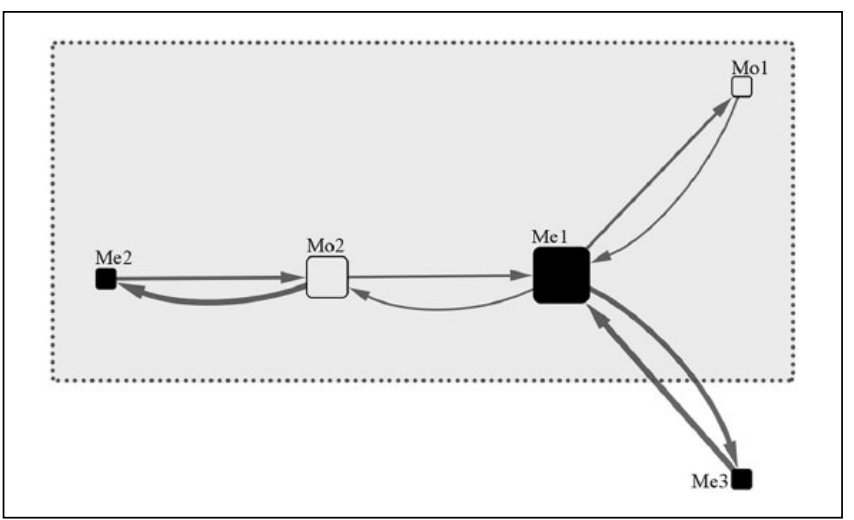

Figure I. Illustration of the size of STEM networks and the centrality of Mentee I in this STEM network.

Note. STEM = science, technology, engineering, and mathematics.

group size $_{\text {grp }}=$ group size $\left._{\text {grp }}-1\right)$. The group size remained unchanged for one-on-one mentoring. With this correction, the size of the STEM networks ranged from 2 to 41 in the one-on-one mentoring condition and from 2 to 77 in the group-mentoring condition.

Centrality in the STEM network. Participants who (a) communicate more about STEM, (b) possess larger STEM networks, and (c) have a greater amount of centrality in these networks have a higher betweenness centrality (Newman, 2001a). To ascertain the position of mentees in their respective STEM networks, we used the Cytoscape add-on CentiScaPe (Version 2.1; Scardoni, Petterlini, \& Laudanna, 2009). Betweenness centrality is hereby defined as "the total number of shortest paths between pairs of actors [= persons] that pass though $i$ [= the considered person]" (Newman, 2001b, p. 2). CentiScaPe determined each mentee's betweenness centrality according to the following algorithm: For each pair of members, the add-on computed the shortest paths between them and counted the total number of shortest paths that pass through the target mentee. If a mentee lies on many of those paths, she receives a high value. If a mentee has a betweenness centrality value of 0 , for example, then she was not located on any of the shortest paths in the STEM network. She is thus located on the edge of the STEM network (or in a STEM network of size 2). The higher her betweenness centrality value, the more different STEM-related network areas one mentee connects through her STEM e-mails (i.e., the more number of shortest paths she is on). We used the directed and weighted option of the betweenness algorithm in CentiScaPe to account for the number of written and received STEM e-mails. Thus, the more STEM e-mails a mentee wrote and received, the more likely those connections (created by those e-mails) were to be chosen for the shortest paths in the network. A high level of centrality thus means that a mentee wrote many STEM e-mails, sent these to a greater number of different persons, and had a central place in the given STEM network. This, in turn, means that a mentee functions as a link between various parts of her network. Figure 1 provides an example. Here, the larger the square, the greater an individual's centrality is within the STEM network. In this case, Me2, Mo1, and Me3 each have a betweenness centrality of 0 , because they lie on the edge of the STEM Network. Mo2 connects the right part of the network with the left part of the network and has a betweenness centrality of 6 (i.e., three shortest paths from left to right, three shortest paths from right to left). With a value of 10 (i.e., 10 shortest paths), Me1 has the highest betweenness centrality in the network depicted in Figure 1. Me1 connects the left and the right parts of the STEM network, as Mo2 also does. However, only Me1 also connects Mol with Me3 and Mo2. Following established procedure, we normalized the betweenness centrality to values between 0 and 1 by dividing the raw score by the maximum possible value (in directional networks $B C_{\max }=(N-2) *(N-1)$, where $N$ is the size of the STEM network and $B C$ stands for betweenness centrality): Thus, in Figure 1, Me1 achieves a final betweenness centrality value of 0.83 ; and $\mathrm{Mo} 2$ achieves 0.5 (for further details, see Opsahl, Agneessens, \& Skvoretz, 2010).

Elective Intentions in STEM. We assessed students' elective intentions in STEM with a five-item scale by Stoeger et al. (2013). Respondents indicated on a 6-point Likert-type scale (with $1=$ strongly disagree and $6=$ strongly agree) how well they could picture themselves choosing a university major in STEM, choosing a STEM subject at school, or pursuing a career in a STEM-related field. Sample item: "I can picture myself majoring in a STEM subject.” Cronbach's $\alpha$ was .79 and .84 for the two measuring points, respectively.

\section{Data Analysis}

We conducted the following analyses in IBM Statistics SPSS (Version 23). First, to compare the effectiveness of one-onone and group mentoring, we compared mentees' STEM communication for both types of mentoring. We compared the normally distributed variable proportion of STEM communication by way of an independent-samples $t$ test. We compared the two nonnormally distributed variables number of sent STEM e-mails and number of STEM words with an independent-samples Mann-Whitney $U$ test. Second, we compared the mentees' STEM-related networking in both mentoring approaches. We compared the nonnormally distributed variables number of STEM contacts, size of STEM networks, and betweenness centrality with independent-samples Mann-Whitney $U$ tests. Third, we analyzed whether the two mentoring approaches had different influences on the mentees' elective intentions with a one-way repeated-measures analysis of variance with two measuring points for the dependent variable elective intentions in STEM with mentoring condition as the between-subjects variable and time as the within-subjects variable (measuring points T1 and T2). We also conducted a paired-samples $t$ test for each mentoring 
Table I. Means and Standard Deviations of STEM Communication, STEM-related Networking, and Elective Intentions in STEM.

\begin{tabular}{lcccc}
\hline & \multicolumn{2}{c}{ One-on-one mentoring $(N=140)$} & \multicolumn{2}{c}{ Group mentoring $(N=74)$} \\
\cline { 2 - 5 } & $M$ & $S D$ & $M$ & \multicolumn{2}{c}{ SD } \\
\hline No. of sent STEM e-mails & 9.38 & 8.84 & 12.55 & 9.94 \\
No. of STEM words & 26.66 & 26.68 & 49.53 & 0.013 \\
Proportion of STEM words & 0.012 & 0.007 & 3.84 & 0.005 \\
No. of STEM contacts & 1.78 & 2.93 & 3.08 \\
Size of the STEM network & 5.21 & 9.57 & 0.22 & 21.53 \\
Centrality in the STEM network & 0.04 & 0.13 & 0.27 \\
Elective Intentions in STEM (TI) & 4.72 & 0.82 & 4.90 & 0.87 \\
Elective Intentions in STEM (T2) & 4.65 & 0.93 & 5.02 & 0.91 \\
\hline
\end{tabular}

Note. STEM = science, technology, engineering, and mathematics.

group to find out whether there was a significant change in elective intentions in STEM between T1 and T2. Fourth, we conducted a multiple linear regression to assess whether the mentees' centrality in their respective STEM networks predicted changes in elective intentions. Here we considered only the participants in the group-mentoring condition $(N=$ 173 ) as this group's betweenness centrality was greater and, furthermore, characterized by a greater amount of variance. Elective intentions in STEM at T2 was the dependent variable. The predictors were elective intentions at T1, as a control variable, and centrality in the STEM network as operationalized by betweenness centrality. There was no significant correlation between the predictors, $r(173)=.07, p>$ .10. We found no outliers within the suggested Cook's distance interval [0, 1] (Cohen, Cohen, West, \& Aiken, 2003). Tests of whether the data met the assumption of collinearity indicated that multicollinearity was not a concern (elective intentions in STEM at T1, tolerance $=0.99, V I F=1.01$; betweenness centrality [trans.], tolerance $=0.99, V I F=1.01$ ). The data met the assumption of independent errors (DurbinWatson's $d=2.01$ ), and the histogram of standardized residuals indicated that the data contained approximately normally distributed errors, as did the normal $P-P$ plot of standardized residuals. The scatterplot of standardized residuals also showed that the data met the assumptions of homogeneity of variance and linearity. However, the residuals were highly correlated with the outcome value. This indicates that some important sources of variance were left out of the model.

\section{Results}

\section{Differences in STEM Communication in One-on- One Versus Group Mentoring}

The proportion of STEM communication was greater in the group-mentoring condition than in one-on-one mentoring. Table 1 provides means and standard deviations. Mentees participating in the group mentoring wrote $33.80 \%$ more STEM e-mails than mentees in the one-on-one approach $(U$ $=3568.00, p<.001, r=.26$ ). Moreover, group-mentoring mentees' e-mails contained, on average, $85.78 \%$ more STEM words than the e-mails written by the one-on-one mentoring mentees $(U=2867.50, p<.001, r=.37)$. The proportion of STEM words (of all written words) in group-mentoring mentees' e-mails was $12.31 \%$ greater than that of the one-on-one mentoring mentees, with the difference attaining marginal significance, $t(191.78)=1.68, p=.094, d=0.24$.

\section{Differences in STEM-Related Networking}

Group-mentoring mentees also showed a greater amount of STEM-related networking in comparison to the one-on-one mentoring mentees. Table 1 provides means and standard deviations. The group-mentoring mentees made, on average, more than twice as many STEM contacts via e-mail than the one-on-one mentoring mentees $(U=1482.00, p<.001, r=$ .63). Group-mentoring mentees had STEM networks that were, on average, $119.19 \%$ larger than those of the one-onone mentoring mentees. In other words, the group-mentoring mentees were in STEM networks that included, on average, six more members than the one-on-one mentoring mentees' STEM networks $(U=2159.00, p<.001, r=.53)$. Groupmentoring mentees achieved a betweenness centrality in their networks that was 5.5 times greater than that achieved by the one-on-one mentoring mentees $(U=2756.00, p<$ $.001, r=.47)$.

\section{Differences in the Increase of Elective Intentions in STEM}

The one-way repeated-measures analysis of variance revealed a significant interaction between type of mentoring (one-onone mentoring vs. group mentoring) and time (T1 vs. T2) on elective intentions in STEM, $F(1,212)=4.84, p=.029, \eta_{p}^{2}=$ .02 . There was also a significant main effect of type of mentoring, $F(1,212)=5.49, p=.020, \eta_{p}{ }^{2}=.03$, but no main effect of time, $\left.F(1,212)=.25, p>.10, \eta_{p}^{2}=.00\right)$. Table 1 provides means and standard deviations. Group-mentoring mentees reported increased elective intentions in STEM after half a 
year of mentoring, $t(73)=1.96, p=.054, d=0.14$, whereas the elective intentions of one-on-one mentoring mentees did not significantly change, $t(139)=-1.36, p>.10, d=0.09$. Before the start of the mentoring program (T1), there was no significant difference in the elective intentions in STEM of students of the two mentoring groups, $t(212)=1.46, p>.10$, $d=0.21$, but 6 months later elective intentions differed significantly, $t(212)=2.85, p=.005, d=0.40$.

\section{Influence of Centrality in the STEM Network on the Increase in Elective Intentions}

A multiple linear regression was conducted to analyze the influence of mentees' centrality in their STEM network on their elective intentions in STEM after 6 months of mentoring. The highly significant model, $F(2,170)=121.68, p<$ .001 , indicates a positive influence of the predictors elective intentions in STEM at T1 $(\beta=.74, p<.001)$ and centrality in the STEM network $(\beta=.16, p=.002)$ on elective intentions in STEM at T2 and explained $59 \%$ of the total variance (adjusted $R^{2}=.58$ ) of the dependent variable. Thus, the more central the position of a mentee was in her STEM network, the higher her elective intentions in STEM were after 6 months of mentoring - even after controlling for the initial elective intentions in STEM. Table 2 provides detailed results.

\section{Discussion}

The purpose of this study was to explore whether group mentoring for talented girls in STEM is more effective than one-onone mentoring. We compared STEM-related communication behavior, STEM-related networking, and changes in elective intentions in STEM for talented girls who had participated either in one-on-one mentoring or in group mentoring for 6 months. The study examined an online mentoring program that started with a one-on-one mentoring approach and then, after some years, switched to a many-to-many group-mentoring approach (Stoeger et al., 2014).

Group mentoring turned out to be more successful on all examined measures. First, talented girls who participated in the group mentoring wrote more STEM e-mails; their e-mails contained more STEM words, both in absolute terms and in relation to all the words they wrote. While this finding does not provide direct evidence that group mentoring is more successful than one-on-one mentoring, the high degree of STEM communication can be viewed as indirect evidence for effective mentoring. Several studies have shown that ontopic communication influences mentoring success (e.g., DuBois et al., 2002; Stoeger et al., 2016).

One reason for the greater STEM communication in the group-mentoring approach might be that school-related STEM topics arose more frequently in the group-mentoring approach as it facilitated regular communication between
Table 2. Summary of the Multiple Linear Regression Analysis for Predicting Elective Intentions in STEM (T2) for Group Mentoring $(N=173)$.

\begin{tabular}{lcrc}
\hline Variable & $\beta$ & \multicolumn{1}{c}{$t$} & \multicolumn{1}{c}{$P$} \\
\hline Constant & & 2.84 & .005 \\
Elective intentions in STEM (TI) & .74 & 14.99 & .000 \\
Centrality in the STEM network & .16 & 3.20 & .002 \\
$R^{2}$ & .59 & & \\
\hline
\end{tabular}

Note. STEM = science, technology, engineering, and mathematics. Adjusted $R^{2}=.58$.

two mentees. As described earlier, the hallmark of the groupmentoring condition was four-person mentoring communities consisting of two mentees and two mentors. The group-mentoring condition may also have facilitated more discussion of various career options in STEM. Even when the two mentors represented the same STEM field (e.g., computer science), their exact professions and areas of specialization usually differed.

Second, group mentoring was also more effective with regard to STEM-related networking. Mentees in the groupmentoring condition made more STEM contacts with other participants, had larger STEM networks, and achieved a more central position within these networks - even after statistically accounting for the greater size of the networks in group mentoring. The findings pertaining to STEM-related networks can also be interpreted only as indirect evidence that group mentoring is more successful than one-on-one mentoring. The interpretation is, however, supported by several studies that describe a relationship between greater amounts of STEM networking and increased numbers of appropriate role models (e.g., Dasgupta, 2011; Stout et al., 2010). An increased number of role models discourages disadvantageous subtyping processes in STEM (Richards \& Hewstone, 2001). More extensive networks of girls and women who are excited about STEM also help discourage perceptions of STEM as being somehow unfeminine (Kessels et al., 2014). Furthermore, increased STEM networking facilitates talent development (Blickle et al., 2009) and the development of more extensive knowledge about STEM professions and majors, in particular when mentees possess a central position within their STEM networks (Leydesdorff, 2007; Newman, 2001b). All these aspects are known to increase STEM participation.

Third, girls in the group-mentoring condition showed a significant increase in their elective intentions in STEM after 6 months, whereas the elective intentions of mentees in the one-on-one mentoring condition did not change. The increase in elective intentions can be interpreted as direct evidence of the group mentoring's effectiveness. The stability of elective intentions in STEM in the one-on-one mentoring condition initially surprised us; previous research examining earlier one-on-one mentoring cohorts had reported increases in 
elective intentions (e.g., Stoeger et al., 2013). The observed increases in previous studies were, however, greater after 1 year of mentoring than after 6 months. It is thus possible that improvements in elective intentions result more quickly in group mentoring. This may reflect group-mentoring participants' more extensive STEM communication and networking (Stoeger et al., 2016).

Fourth, increasing mentees' positional centrality appears to be effective for encouraging girls in STEM. The more central the position of mentees in their respective STEM networks, the more they are able to picture themselves selecting a major or a career in STEM or choosing a STEM activity. Network research sheds light on these correlations. Individuals with similar interests cluster in networks (McPherson, SmithLovin, \& Cook, 2001). Mentees with a high degree of (betweenness) centrality link clusters structured around similar interests (Leydesdorff, 2007; Newman, 2001b). They receive richer information about STEM and, by way of extensive interaction with other individuals with STEM interests, become more motivated for STEM (Freeman et al., 1979). This should effect positive changes in elective intentions in STEM.

\section{Limitations and Future Research}

The group-mentoring approach investigated in our study proved more effective than the one-on-one approach. The finding clearly does not, however, justify the general conclusion that group mentoring is inherently more effective than one-on-one mentoring. Our results must be viewed in light of our examination of a very special form of group mentoring - a many-to-many approach in which two mentoring dyads form one four-person mentoring community. This approach harnesses various advantages of group mentoring (e.g., more extensive communication and networking among participants) while avoiding a number of the drawbacks associated with group mentoring. The matching of a specific mentee with a specific mentor hinders responsibility diffusion; the overall low number of individuals in a mentoring community (four) checks cognitive overload (Dunbar, 1993).

We note three limitations. First, our study does not provide insight into whether variations of our chosen group-mentoring approach would be as effective. Future research should examine, for instance, whether a fundamentally tetradic structure-in which two mentees and two mentors are grouped together without internal dyadic grouping - might also be a propitious approach. The question is also open as to whether there is a certain group size as of which drawbacks such as responsibility diffusion or cognitive overload arise.

Second, although several 100 mentees and mentors participated annually in the STEM mentoring program described here, only a considerably smaller proportion (about 20\%) of the participants completed the online scale (as requested) and exchanged e-mails about STEM on a regular basis. Future research should investigate the extent to which these mentees differed from other, less active participants. Previous studies of earlier mentoring cohorts in the same program do, however, suggest that there are large differences in mentoring effectiveness-depending on how intensively participants used the mentoring platform and which communication tools they used (e.g., Heilemann, 2016; Stoeger et al., 2016). Nevertheless, e-mails offered a particularly appropriate medium of communication for comparing one-on-one and group mentoring, because e-mail was the preferred medium of communication between mentees and mentors (Heilemann, 2016). The other communication media were used more for communication between participants outside of the mentoring dyad and outside of the four-person mentoring community. Future research should consider these differences in more detail.

Third, we assessed only the quantity of STEM communication. Our chosen method does not allow for observations about the quality or specific topics within STEM-related communication. Future studies should, therefore, investigate whether the STEM contents differed according to the chosen online mentoring approach. For example, it would be helpful to understand the extent to which STEM-related discussions were about problems or about interesting topics in STEM. Specific topics and sentiments may influence the mentoring outcomes.

\section{Key Implications}

Our study provides important indications that the type of group mentoring we examined may be more effective than one-on-one mentoring for encouraging talented girls' enthusiasm for STEM. At first glance, the effect size of the interaction effect between mentoring approach and time as well as the effect size of the increase in elective intentions in the group-mentoring condition appear relatively small. It must be kept in mind, however, that the interaction effect is not for comparisons of participants with a control group that did not receive mentoring (e.g., Stoeger et al., 2013; Stoeger et al., 2016). Rather, the interaction effect is for comparisons over time of two groups of participants who participated in very similar interventions. Hence, a rather small effect size is to be expected.

Finally, we draw our readers' attention to a key hallmark of our study. Despite the possibility of unrecognized cohort effects, our study is novel in that both groups of mentees participated in two variants of an otherwise identical online mentoring program. This suggests that the differences we observed in mentoring outcomes may well be specifically reflecting the type of mentoring approach (one-on-one vs. group mentoring) rather than other program or participant characteristics. Our findings thereby provide initial evidence that the many-to-many group-mentoring approach as implemented in the mentoring program we examined is a viable option for encouraging talented girls' interest in STEM. 


\section{Declaration of Conflicting Interests}

The author(s) declared no potential conflicts of interest with respect to the research, authorship, and/or publication of this article.

\section{Funding}

The author(s) disclosed receipt of the following financial support for the research, authorship, and/or publication of this article: This research was supported in part by grants from the German Federal Ministry for Education and Research.

\section{References}

Bierema, L. L., \& Merriam, S. B. (2002). E-mentoring: Using computer mediated communication to enhance the mentoring process. Innovative Higher Education, 26, 211-227. doi:10.1023/A:1017921023103

Blickle, G., Witzki, A. H., \& Schneider, P. B. (2009). Mentoring support and power: A three year predictive field study on protege networking and career success. Journal of Vocational Behavior, 74, 181-189. doi:10.1016/j.jvb.2008.12.008

Bozeman, B., \& Feeney, M. K. (2007). Toward a useful theory of mentoring: A conceptual analysis and critique. Administration \& Society, 39, 719-739. doi:10.1177/0095399707304119

Cheryan, S., Drury, B. J., \& Vichayapai, M. (2013). Enduring influences of stereotypical computer science role models on women's academic aspirations. Psychology of Women Quarterly, 37, 72-79. doi:10.1177/0361684312459328

Cohen, J., Cohen, P., West, S. G., \& Aiken, L. S. (2003). Applied multiple regression/correlation analysis for the behavioral sciences. Mahwah, NJ: Lawrence Erlbaum.

Dasgupta, N. (2011). Ingroup experts and peers as social vaccines who inoculate the self-concept: The stereotype inoculation model. Psychological Inquiry, 22, 231-246. doi:10.1080/1047 840X.2011.607313

DuBois, D. L., Holloway, B. E., Valentine, J. C., \& Cooper, H. (2002). Effectiveness of mentoring programs for youth: A meta-analytic review. American Journal of Community Psychology, 30, 157-197. doi:10.1023/A:1014628810714

DuBois, D. L., \& Karcher, M. J. (2005). Handbook of youth mentoring. Thousand Oaksd, CA: Sage.

DuBois, D. L., Portillo, N., Rhodes, J. E., Silverhorn, N., \& Valentine, J. (2011). How effective are mentoring programs for youth? A systematic assessment of the evidence. Psychological Science in the Public Interest, 12, 57-91. doi:10.1177/1529100611414806

Dunbar, R. I. M. (1993). Coevolution of neocortical size, group size and language in humans. Behavioral and Brain Sciences, 16, 681-735. doi:10.1017/S0140525X00032325

Ensher, E., Heun, C., \& Blanchard, A. (2003). Online mentoring and computer-mediated communication: New directions in research. Journal of Vocational Behavior, 63, 264-288. doi:10.1016/S0001-8791(03)00044-7

Faul, F., Erdfelder, E., Buchner, A., \& Lang, A.-G. (2009). Statistical power analyses using $\mathrm{G}^{*}$ Power 3.1: Tests for correlation and regression analyses. Behavior Research Methods, 41, 1149-1160. doi:10.3758/BRM.41.4.1149

Freeman, L. C., Roeder, D., \& Mulholland, R. R. (1979). Centrality in social networks: II. Experimental results. Social Networks, 2, 119-141.
Frenzel, A. C., Goetz, T., Pekrun, R., \& Watt, H. M. G. (2010). Development of mathematics interest in adolescence: Influences of gender, family and school context. Journal of Research on Adolescence, 20, 507-537. doi:10.1111/j.15327795.2010.00645.x

Heilemann, M.(2016). Gütekriterien diktionärsbasierter Textanalysen zur Erfassung domänenspezifischer Kommunikationsinhalte [Quality criteria of dictionary-based text analysis for measuring domain-specific communication]. Berlin, Germany: Logos.

Huizing, R. L. (2010). Mentoring together: A literature review of group mentoring. Mentoring \& Tutoring: Partnership in Learning, 20, 27-55. doi:10.1080/13611267.2012.645599

Kalwarski, T., Mosher, D., Paskin, J., \& Rosato, D. (2007). Best jobs in America. CNNMoney.com. Retrieved from http:// money.cnn.com/pf/best-jobs/2017/list/

Kessels, U., Heyder, A., Latsch, M., \& Hannover, B. (2014). How gender differences in academic engagement relate to students' gender identity. Educational Research, 56, 220-229. doi:10.10 80/00131881.2014.898916

Kuperminc, G. P., \& Thomason, J. D. (2013). Group mentoring. In D. L. DuBois \& M. J. Karcher (Eds.), Handbook of youth mentoring (2nd ed., pp. 273-290). Thousand Oaks, CA: Sage.

Leydesdorff, L. (2007). Betweenness centrality as an indicator of the interdisciplinarity of scientific journals. Journal of the American Society for Information Science and Technology, 58, 1303-1319. doi:10.1002/asi.20614

McPherson, M., Smith-Lovin, L., \& Cook, J. M. (2001). Birds of a feather: Homophily in social networks. Annual Review of Sociology, 415-444. doi:10.1146/annurev.soc.27.1.415

Miller, H. M., \& Griffiths, M. D. (2005). E-mentoring. In D. L. DuBois \& M. J. Karcher (Eds.), Handbook of youth mentoring (pp. 300-313). Thousand Oaks, CA: Sage.

Newman, M. E. J. (2001a). Scientific collaboration networks: I. Network construction and fundamental results. Physical Review E, 64, 016131. doi:10.1103/PhysRevE.64.016131

Newman, M. E. J. (2001b). Scientific collaboration networks. II. Shortest paths, weighted networks, and centrality. Physical Review E, 64, 016132. doi:10.1103/PhysRevE.64.016132

Olszewski-Kubilius, P. (2009). Special schools and other options for gifted STEM students. Roeper Review, 32, 61-70. doi:10.1080/02783190903386892

O’Neill, D. K., Asgari, M., \& Dong, Y. D. (2011). Trade-offs between perceptions of success and planned outcomes in an online mentoring program. Mentoring \& Tutoring, 19, 45-63. doi:10.1080/13611267.2011.543570

O’Neill, D. K., Wagner, R., \& Gomez, L. M. (1996). Online mentors: Experimenting in science class. Educational Leadership, 54(3), 39-42.

Opsahl, T., Agneessens, F., \& Skvoretz, J. (2010). Node centrality in weighted networks: Generalizing degree and shortest paths. Social Networks, 32, 245-251. doi:10.1016/j. socnet.2010.03.006

Packard, B. W. (2003). Web-based mentoring: Challenging traditional models to increase women's access. Mentoring \& Tutoring, 11, 53-65. doi:10.1080/1361126032000054808

Pennebaker, J. W., Booth, R. E., \& Francis, M. E. (2007). Operator's manual: Linguistic inquiry and word count: LIWC2007. Austin, TX: LIWC.net. 
Penny, C., \& Bolt, D. (2009). eMentoring: Connecting teacher candidates with $\mathrm{K}-12$ students from urban schools. International Journal of Instructional Technology \& Distance Learning, 5, 169-181.

Pfund, C., Pribbenow, C. M., Branchaw, J., Lauffer, S. M., \& Handelsman, J. (2006). The merits of trading mentors. Science, 311, 473-474. doi:10.1126/science.1123806

Richards, Z., \& Hewstone, M. (2001). Subtyping and subgrouping: Processes for the prevention and promotion of stereotype change. Personality and Social Psychology Review, 5, 52-73. doi:10.1207/S15327957PSPR0501_4

Scardoni, G., Petterlini, M., \& Laudanna, C. (2009). Analyzing biological network parameters with CentiScaPe. Bioinformatics, 25, 2857-2859. doi:10.1093/bioinformatics/btp517

Schoon, I., \& Eccles, J. S. (Eds.). (2014). Gender differences in aspirations and attainment: A life course perspective. Cambridge, England: Cambridge University Press.

Shannon, P., Markiel, A., Ozier, O., Baliga, N. S., Wang, J. T., Ramage, D., \& Ideker, T. (2003). Cytoscape: A software environment for integrated models of biomolecular interaction networks. Genome Research, 13, 2498-2504. doi:10.1101/ gr. 1239303

Statistisches Bundesamt. (2015). Statistisches Jahrbuch 2015 [2015 statistical almanac]. Retrieved from https://www. destatis.de/DE/Publikationen/StatistischesJahrbuch/ StatistischesJahrbuch2015.pdf

Stoeger, H., Duan, X., Schirner, S., Greindl, T., \& Ziegler, A. (2013). The effectiveness of a one-year mentoring program for girls in STEM. Computers \& Education, 69, 408-418. doi:10.1016/j.compedu.2013.07.032

Stoeger, H., Schirner, S., Laemmle, L., Obergriesser, S., Heilemann, M., \& Ziegler, A. (2016). A contextual perspective on talented female participants and their development in extracurricular STEM programs. Annals of the New York Academy of Sciences, 1377, 53-63. doi:10.1111/nyas.13116

Stoeger, H., Ziegler, A., Buschhaus, F., Greindl, T., Groß, C., Heilemann, M., . . . Zsak, N. (2014). Von CyberMentor zu CyberMINT-Communities: Acht Jahre erfolgreiche MINTMädchenförderung [From CyberMentor to CyberMINT communities: Eight years of successful gifted education provision for girls in STEM]. Regensburg, Germany: Druck Team.

Stout, J. G., Dasgupta, N., Hunsinger, M., \& McManus, M. A. (2010). STEMing the tide: Using ingroup experts to inoculate women's self-concept in science, technology, engineering, and mathematics (STEM). Journal of Personality and Social Psychology, 100, 255-270. doi:10.1037/a0021385

Subotnik, R. F., Edmiston, A. M., Cook, L., \& Ross, M. D. (2010). Mentoring for talent development, creativity, social skills, and insider knowledge: The APA catalyst program. Journal of Advanced Academics, 21, 714-739. doi:10.1177/19322 02X1002100406

Wang, M.-T., Eccless, J., \& Kenny, S. (2013). Not lack of ability but more choice: Individual and gender differences in choice of careers in science, technology, engineering, and mathematics. Psychological Science, 24, 770-775. doi:10.1177/ 0956797612458937

\section{Author Biographies}

Heidrun Stoeger, $\mathrm{PhD}$, is a full professor of educational sciences at the University of Regensburg, Germany. She holds the Chair for School Research, School Development, and Evaluation. She is Vice President of the International Research Association for Talent Development and Excellence. She is also a member of the editorial board of the German Journal of Talent Development and was editor in chief of the journal High Ability Studies (2007-2014). She has published more than 200 articles, chapters, and books on giftedness, self-regulated learning, motivation, fine motor skills, and teacher education. She is member of several national and international scientific boards and expert commissions in the field of giftedness research and gifted education.

Manuel Hopp is a research associate at the chair of educational psychology and research on excellence of the University of Erlangen-Nuremberg, working in an e-mentoring project called CyberMentor. His research interests include (social) network analysis and gifted education.

Albert Ziegler, $\mathrm{PhD}$, is Chair Professor of Educational Psychology and Research on Excellence at the University of ErlangenNuremberg, Germany. He is the founding director of the statewide Counselling and Research Centre for the Gifted. He has published approximately 300 books, book chapters, and articles in the fields of talent development, excellence, educational psychology, and cognitive psychology. Presently he serves as Secretary General of the International Research Association for Talent Development and Excellence, as Vice President of the European Council for High Ability, as the chairman of the European Talent Support Network, and as editor in chief of the journal High Ability Studies. 